\title{
Absence of Spectral Peaks in Short-Period Oscillations from the Chilean Earthquake
}

\section{Hitoshi Takeuchi, Hiroo Kanamori, and Masanori Saito \\ Geophysical Institute, University of Tokyo, Tokyo, Japan}

On the occasion of the great Chilean earthquake of May 1960, various modes of free oscillations of the earth were observed: spheroidal oscillations of wave number $n=2$ (period 53 $\mathrm{min})$ to 38 (3.7 $\mathrm{min}$ ) [Benioff et al., 1961; Ness et al., 1961; Alsop et al., 1961; Bogert, 1961] and torsional oscillations of $n$ up to 24 (5.2 min) [Bolt and Marussi, 1962; Brune et al., 1961]. From a rather negative result that the shorter-period oscillations were not well observed, we try here to deduce some conclusions regarding the earth's upper mantle structure or the oscillation mechanism of the earthquake. The result may be due to horizontal inhomogeneities of the upper mantle of the earth making the resolution of spectral peaks in shorterperiod oscillations difficult, or it may be due to weak excitation of shorter-period oscillations by the source.

To study the first possibility, we compare free periods for two extreme earth models, the Gutenberg model, which has a typical continental mantle structure, and the 8099 model by Dorman et al. [1960], which has a typical oceanic structure. The periods of spheroidal oscillations of $n=40$ for the two models are 210.6 and $208.6 \mathrm{sec}$, respectively [Takeuchi et al., 1962], a difference of $2.0 \mathrm{sec}$. On the other hand, the difference of periods between $n=40$ and 41 spheroidal oscillations is $4.2 \mathrm{sec}$ [Pekeris et al., 1961]. Thus we see that for the spheroidal oscillations the horizontal inhomogeneities in the upper mantle structure are large enough to make the shorter-period resolution difficult. The periods of torsional oscillations of $n=25$ for the above two models are 300.2 and $298.3 \mathrm{sec}$, respectively. The difference is $1.9 \mathrm{sec}$ against a difference of $10.2 \mathrm{sec}$ between $n=24$ and 25 torsional oscillations. Thus it seems difficult to explain the lack of shorter-period torsional oscillations by the horizontal inhomogeneities.

We now examine the second possibility. It is well known that if earthquake origin is of the impulsive type of duration time $T$, amplitudes of component oscillations with periods shorter than $T$ become small. Thus the lack of shorterperiod oscillations may be due to the duration time of the Chilean earthquake being $4 \mathrm{~min}$ (spheroidal oscillations) to $5 \mathrm{~min}$ (torsional oscillations) or at least of this order of mag. nitude. According to Benioff et al. [1961] a fault of about $1000-\mathrm{km}$ length and of rupture velocity 3 to $4 \mathrm{~km} / \mathrm{sec}$ was made at the time of the Chilean earthquake. This seems to imply a duration time of the above order of magnitude Although we have no compelling reason to exclude any other factors, such as instrumental characteristics, we think that the horizontal inhomogeneities of the upper mantle and the impulsive character of the origin (probably the latter) are responsible for the lack of spectral peaks in shorter-period oscillations of the earth.

\section{ReFERENCES}

Alsop, L. E., G. H. Sutton, and M. Ewing, Free oscillations of the earth observed on strain and pendulum seismographs, J. Geophys. Res., 66, 631-641, 1961.

Benioff, H., F. Press, and S. Smith, Excitation of the free oscillation of the earth by earthquakes, J. Geophys. Res., 66, 605-619, 1961.

Bogert, B. P., An observation of free oscillations of the earth, J. Geophys. Res., 66, 643-646, 1961.

Bolt, B. A., and A. Marussi, Eigenvibrations of the earth observed at Trieste, Geophys. J., 6, 299311, 1962.

Brune, J. N., H. Benioff, and M. Ewing, Longperiod surface waves from the Chilean earthquake of May 22, 1960, recorded on linear strain seismographs, J. Geophys. Res., 66, 2895-2910, 1961.

Dorman, J., M. Ewing, and J. Oliver, Study of shear-velocity distribution in the upper mantle by mantle Rayleigh waves, Bull. Seismol. Soc. Am., 50, 127-147, 1960.

Ness, N., J. Harrison, and L. Slichter, Observations of the free oscillations of the earth, J. Geophys. Res., 66, 621-629, 1961.

Pekeris, C. L., Z. Altermann, and H. Jarosch, Com. parison of theoretical with observed values of the periods of free oscillation of the earth, Proc. Natl. Acad. Sci., U. S., 47, 91-98, 1961.

Takeuchi, H., M. Saito, and N. Kobayashi, Study of shear velocity distribution in the upper mantle by mantle Rayleigh and Love waves, $J$. . Geophys. Res., 67, 2831-2839, 1962.

(Received May 23, 1963.) 